\title{
Feminismo y posmodernidad
}

María Teresa ZUBIAURRE-WAGNER Instituto Tecnológico Autónomo de México Universidad Nacional Autónoma de México

En primer lugar, hemos de atrevernos con las grandes preguntas, aunque las respuestas vayan a ser necesariamente resumidas: ¿qué es el posmodernismo, o la posmodernidad, ' $y$ qué es el feminismo?

La posmodernidad es el ahora, nuestro mundo y cultura contemporáneos, desencantados del progreso, desconfiados con la historia, sin fe en el futuro. Con la posmodernidad se derrumban los grandes mitos que tan laboriosamente construyó la razón ilustrada. Primero muere Dios a manos de Nietzsche, luego, el autor, como hace varias décadas lo anunciaron Barthes y Foucault ya postestructuralistas, y más tarde -así lo quieren los filósofos de esta segunda y desilusionada mitad de siglo- el propio sujeto.

Los grandes dogmas, las grandes verdades universales, los metarrelatos lyotardianos se convierten en el hazmerreír de los posmodernos. Se proclama el "fin de la historia" y a esa "Historia" con mayúsculas se le oponen las pequeñas historias, los anales no escritos de los vencidos. ${ }^{2}$ La cotidianidad, es decir, la vida privada de una época, se recoge en grandes volúmenes. ${ }^{3}$ Importan, de pronto, los "márgenes"; importan las otras razas, las otras clases socia-

${ }^{1}$ Los conceptos "posmodernidad" y "posmodernismo" (y de las versiones inglesas "Posmodernity" y "Posmodernism") se utilizan con frecuencia de forma indistinta. Nosotros preferimos el uso de "posmodernidad" porque, en líneas generales, es término con el que suele designarse ( $y$ decimos "suele", porque no hay consenso) al periodo posmoderno en su totalidad, no sólo como manifestación artística-cultural y filosófica (eso seria el "posmodernismo") sino también como fenómeno sociológico y político.

Los textos de Hutcheon y de Rodríguez Magda citados en la bibliografia contienen mayor información sobre la vigente polemica terminológica.

${ }^{2}$ Para una reflexión más profunda sobre el concepto posmoderno de "historia" remitimos a los ensayos de Francis Fukuyama y Gianni Vattimo citados en la bibliografia.

${ }^{3}$ Sirva de ejemplo de ese nuevo interés por la cotidianidad la magna obra de Philippe Ariès y George Duby citada en la bibliografia. 
les; importa el otro sexo. Importa, por primerisima vez, el otro en general, la así llamada "otredad".

La filosofia posmoderna abandona, decidida, las mayúsculas, y con letra pequeña eleva en su escritura el sentimiento sobre la razón, la opinión sobre la idea, la artesanía sobre el arte, lo particular sobre lo universal, lo privado y personal sobre lo público y social, las minorías sobre las mayorias, el contexto local sobre los contextos globales, lo débil sobre lo fuerte, lo efimero sobre lo estable y duradero. El propio pensamiento filosófico, cansado de las viejas rigideces y de los obsoletos códigos de honor, se hace ecléctico, coquetea con otros estilos (se vuelve, con frecuencia, literario y poético), se lanza, valiente, a la exploración de nuevos temas. "Ese nivel altamente especulativo e interdisciplinar de la discusión más reciente tiene como ejes geográficos de pensamiento el postestructuralismo francés, la teoría crítica alemana y la literatura artística norteamericana". ¿Quiénes son, pues, los representantes más señalados de tales escuelas?

De entre los estadounidenses, destacan Susan Sontag, Leslie Fiedler e Ihab Hassan, pioneros de la posmodernidad que allá por los años sesentas creen observar en las artes visuales y literarias un nuevo impulso renovador, y el inicio - por decirlo con palabras de Herbert Marcuse - de "una nueva sensibilidad".

De entre los alemanes es de obligada referencia Jürgen Habermas, filosofo de la Escuela de Frankfurt que en la década de los ochentas, con motivo de la rápida expansión del pensamiento posmoderno, entró en una agitada polémica con Jean-Francois Lyotard. Pero también los filósofos de la primera generación de la Escuela de Frankfurt (sobre todo Herbert Marcuse, Theodor Adorno y Max Horkheimer), aunque nunca se llamaran a si mismos "posmodernos", son vistos como primos hermanos (o quizás, abuelos) de los posmodernos de ahora. La dialéctica de la Ilustración, obra seminal y conjunta de Adorno y de Horkheimer, es considerada la biblia de la filosofia posmoderna, puesto que en ella se emprende por primera vez una desconstrucción metódica y profundamente razonada del espíritu ilustrado.

Entre los franceses, la posmodernidad se ha vuelto epidemia contagiosa. Son considerados postestructuralistas y, por ende, posmodernos, Michel Foucault, el gran epistemólogo del poder; Gilles Deleuze y Félix Guattari, "defensores entusiastas de una micropolitica del deseo"s como única estrategia liberadora en la presente época postindustrial; Jacques Derrida, padre de la

'Modernidad y posmodernidad, ed. de Josep Picó, p. 13.

5 Todd Best y Douglas Kellner, Postmodern Theory. Critical Interrogations, p. 76. 
desconstrucción y voz airada que denuncia, pertinaz, la "metafísica de la presencia"; Jean Baudrillard, filósofo ciertamente monotemático, cuyas reflexiones giran obsesivamente alrededor de la sociedad de los medios de comunicación, de la hiperrealidad y del simulacro, y, finalmente, Jean-Francois Lyotard, insistente detractor de los "metarrelatos" y las narrativas legitimizadoras.

Fuera ya del ámbito galo, falta citar al italiano Gianni Vattimo, fundador del llamado "pensiero debole", asi como a los "neomarxistas" (entre los que destacan Frederic Jameson y Ernesto Laclau), y a los neoconservadores o apocalípticos, a la manera de Daniel Bell o de Gilles Lipovetsky.

Todas estas tendencias filosóficas, a pesar de sus divergencias y sus enredos, brotan del mismo malestar - el malestar ante los desmanes de la weberiana razón instrumental - y se alimentan de la misma realidad. La sociedad que intentan comprender es precisamente la nuestra, la postindustrial, la era de la telemática, del consumo, de la muerte del comunismo y del violento brote del sida. Pero la realidad contra la que reacciona el pensamiento contemporáneo no es tanto la posmoderna, sino la moderna. El chivo expiatorio será siempre ese monstruo de dos cabezas (una es la razón ilustrada, la otra es la modernidad) que se miran incesantemente a los ojos.

Aunque el feminismo no nace con la sociedad postindustrial, sino que debe su origen a los primeros movimientos sufragistas en la era de la rápida industrialización moderna, lo cierto es que con la posmodernidad el pensamiento feminista se enriquece, se afianza a la vez que se diversifica y llega, probablemente, a su definitiva madurez. Ello no es óbice para que frente a la modernidad, frente a las consecuencias de la razón ilustrada, las feministas reaccionen con mucha menos virulencia y mucha más ambigüedad que los posmodernos.

Los diferentes matices de la reacción feminista ante la herencia ideológica del Siglo de las Luces constituyen asunto de capital importancia para la correcta interpretación del malavenido matrimonio del feminismo con la posmodernidad. Pero antes se hace obligado ofrecer a las lectoras una breve explicación de lo que es el movimiento feminista. Baste, por el momento, la definición más simple, ese primer cimiento sobre el que la crítica feminista (en su doble vertiente moderna y posmoderna) ha ido acumulando ideas cada vez más complejas. Por lo pronto, el feminismo sigue siendo, y lo será por siempre, esa lucha por la liberación de la mujer y su igualdad (social, política y sexual) con el hombre que desde el siglo XIX vienen librando unas pocas (aunque cada vez somos más), con resultados muchas veces espectaculares, pero aún insatisfactorios. ¿Quiénes piensan en clave feminista y hacen escuela? Fundamentalmente las francesas, más teóricas, más sesudas, y las norteamericanas, siempre pragmáticas y poco inclinadas a las elucubraciones filosóficas. 
En 1988, Janet Todd iniciaba su Historia de la crítica literaria feminista con la siguiente afirmación: "Se ha puesto de moda criticar, y aún burlarse de la crítica feminista estadounidense, cuyos planteamientos, de carácter eminentemente sociohistórico, son tildados de ingenuos y de simplistas, frente a la mayor sofisticación teórica del feminismo francés". ${ }^{6}$ Pero la ya tradicional distinción (que injustamente favorece a una práctica feminista sobre otra) entre un feminismo histórico-empírico (atribuido a las estadounidenses) y un feminismo ahistórico-teórico (identificado con las francesas) que bebe de las fuentes de la desconstrucción y del psicoanálisis, se sostiene con dificultad. En primer lugar, se hace necesario, hoy más que nunca, romper una lanza en favor de ese feminismo histórico, social y socialista de los primeros tiempos: la sutileza y la complejidad del actual (y posmoderno) pensamiento feminista debe su existencia al valiente (y moderno) pragmatismo de las primeras sufragistas inglesas y a la no menos resoluta y laboriosa revisión de la historia iniciada por las existencialistas francesas. $Y$, en segundo lugar, hay que decir que estos dos feminismos de los que tanto se ha hablado, y que en realidad no aparecen como simultáneos sino como consecutivos en el transcurso de la historia (al enfoque pragmático le sigue la perspectiva teórica), constituyen en realidad dos modernas generaciones cada vez más empalidecidas, a las que una tercera y posmoderna generación saluda sin nostalgia:

Una nueva, una tercera generación está, ahora, constituyéndose. El uso que doy al concepto de generación no evoca tanto una cronología como un espacio significante o espacio mental que es a la vez cuerpo y deseo. La tercera generación, al ser antes que nada una nueva "actitud", puede por ello mismo muy fácilmente convivir, y hasta es deseable que lo haga, con las dos generaciones previas, incluso puede darse el caso, por qué no, de que aparezcan las tres entrelazadas. En esa tercera actitud, que defiendo con calor - ¿con la que sueño?-, la dicotomía hombre/mujer entendida como lucha entre dos fuerzas rivales puede considerarse obsoleta y perteneciente al ámbito de la metafisica. ¿Qué significado puede realmente encerrar el concepto de "identidad", incluso de "identidad sexual", en un nuevo terreno científico y teórico en el que la propia noción de identidad se pone en entredicho? ${ }^{7}$

La pensadora francesa supo ser profética: pronosticó lo que efectivamente ha ocurrido y se ha consolidado en el umbral del siglo XXI. La identidad es

6 Janet TODD, Feminist Literary Theory, p. 1.

7 Julia KrISTEVA, "Women's Time", en Feminisms. An Anthology of Literary Theory and Criticism, ed. de R. Warhol y D. Price HerndL, p. 458. 
concepto, efectivamente, cada vez más precario, que se resuelve en ese plural tan socorrido y tan preciado a la posmodernidad: frente a la identidad (blanca, masculina, occidental), las identidades; frente a la diferencia (separadora de los dos sexos), la libre y variopinta combinación de las diferencias escritas con minúscula.

Veamos cómo esas minúsculas y esos plurales invaden igualmente el feminismo posmoderno. Linda Hutcheon, en un capitulo de The Politics of Postmodernism dedicado a "la posmodernidad y los feminismos", explica de la siguiente manera ese plural tan poco ortodoxo:

Es [un plural] tan disonante como acertado: además de haber tantos feminismos como feministas hay sobre la faz de la tierra, prevalece en la actualidad esa punzante sensación de que efectivamente no se ha llegado a un consenso cultural en lo que a la representación de la figura femenina se refiere. Como observa Catherine Stimpson, son varias las perspectivas que convergen en la historia del pensamiento feminista: por un lado, se dice de las convencionales representaciones de lo femenino que son inexactas y que están adulteradas; otra perspectiva ensaya la generación y producción de representaciones adecuadas de la mujer; por fin, hay enfoques que insisten en la necesidad de representar las diferencias que separan a las mujeres, diferencias que son de orientación sexual, edad, raza, clase social, etnia, y nacionalidad. El concepto de "feminismos", como signo verbal que señala esa diferencia y sugiere la idea de pluralidad, es, seguramente, el más adecuado para designar, no tanto un consenso, como una multiplicidad de puntos de vista aglutinados alrededor de un denominador común. ${ }^{8}$

Reconocer, aceptar y aun buscar la diferencia significa, efectivamente, comportarse a la manera posmoderna. El feminismo, que en sus orígenes sólo toleraba una diferencia, aquella que separaba al sexo masculino del femenino, y que se complacia en una unidad femenina a todas luces ficticia, ${ }^{9}$ ahora, no obstante, reconoce gustoso su propia heterogeneidad. Es más, el pensamiento feminista de las últimas décadas ha sabido nutrirse de ese reconocimiento de

${ }^{8}$ Linda Hutcheon, The Politics of Postmodernism, p. 141.

9 "Gender [...] is so thoroughly fragmented by race, class, historical particularity, and individual difference, as to self-destruct as an analytical category. The 'bonds of womanhood' [...] is a feminist fantasy, born out of ethnocentrism of white, middleclass academics" (Susan BoRDo, "Feminism, Postmodernism and Gender-Scepticism", en Feminism/Postmodernism, ed. de Linda J. Nicholson, p. 133). 
su multiplicad y diversidad para establecer nuevas alianzas: la trinidad - $\tan$ afin al pensamiento moderno- a la que inevitablemente se adscribe la teoría feminista es la de raza, clase y género ("race, class and gender").

Por estas razones, y por otras que indicaremos más adelante, feminismo y posmodernidad están emparentados. Son considerados por muchos "dos de las corrientes político-culturales más importantes de la última década". ${ }^{10}$ También para Waugh, hablar de feminismo y de posmodernidades es hablar de dos prácticas filosóficas, de dos pensamientos que ya en los años setentas supieron "alterar radicalmente la forma en que se entiende y percibe la cultura moderna"."

Esta coincidencia en el tiempo viene acompañada de otras coincidencias, de otros rasgos compartidos. Así, tanto el feminismo como la posmodernidad (en su doble aspecto filosófico-teórico y de acción política) atacan con energía los postulados nacidos de una "experiencia-patrón", es decir, de esa experiencia que es inevitablemente masculina, blanca, occidental y de clase media. (La ironía está en que los filósofos posmodernos son -casi sin excepción- hombres, blancos, occidentales y de clase media: pero eso ya es harina de otro costal.)

Tanto el feminismo como la posmodernidad se afanan en despojar a lo estético de su aura, ${ }^{12}$ de ese prurito de autonomía que el arte heredó del romanticismo y del simbolismo; toda manifestación estética, pues, contiene — según las feministas y los posmodernos- ese germen delator que exige una revisión critica y una cuidadosa desconstrucción del texto.

Barbara Creed cita el conocido trabajo de Owens y ofrece de manera resumida el jubiloso recuento que éste hace de las cualidades compartidas por ambos pensamientos: según el crítico, hay muchas áreas en las que el feminismo no solamente es compatible con el pensamiento posmoderno sino que puede decirse que forma parte de él: así, las dos corrientes respaldan la hipótesis lyotardiana según la cual, en nuestros tiempos, se inicia una manifiesta crisis de la función legitimizadora de los metarrelatos, esas grandes narrativas con las que se construye la identidad de Occidente; tanto unos (los posmodernos) como las otras (las feministas) ensayan una "crítica de la representación", de ese sistema de poder que autoriza ciertas representaciones a la par que "bloquea"

${ }^{10}$ Nancy Fraser y Linda Nicholson, "Crítica social sin filosofia: un encuentro entre el feminismo y el posmodernismo", en Feminismo y postmodernismo, ed. de Linda J. Nicholson, p. 7.

11 Patricia Waugh, Practising Postmodernism. Reading Modernism, p. 125.

$12 \mathrm{El}$ concepto de arte aurático se consagra y explica en el ensayo de Benjamin citado en la bibliografia. 
o invalida otras; coinciden los dos en que "los sistemas occidentales sólo admiten, a la hora de representar la realidad, una sola visión, la del sujeto masculino"; en ambas tendencias se observa, por fin, un obstinado rechazo del pensamiento "binario", esa forma de interpretación del mundo que funciona con oposiciones. ${ }^{13}$

Derrida llama a este modo filosófico-hermenéutico "la metafísica de lo binario" y observa muy acertada y "feministamente" que la descomposición de un todo en dos elementos enfrentados nunca es ingenua, sino profundamente ideológica, amén de descriminatoria: el valor no se reparte entre los dos componentes de manera equitativa, ya que uno de ellos aparecerá siempre subordinado al otro. No hace falta señalar cuál de los polos de los siguientes binomios (civilización/naturaleza; sujeto/objeto; hombre/mujer) sale claramente favorecido en la cultura de occidente..$^{14}$

Pero volvamos a esas posturas compartidas por feministas y posmodernos: Creed añade que "ambos ponen énfasis en la 'diferencia', antes que en la igualdad". Los dos - concluyen ella y Owens - buscan borrar los límites que separan la teoría de la práctica, a la vez que proponen un método de estudio y de acercamiento a la realidad de carácter interdisciplinario, destinado a resolverse en "una actividad simultánea llevada a cabo desde múltiples frentes". ${ }^{15}$

A partir de estas coincidencias y de estos intereses y preocupaciones compartidos, surgen, sin embargo, las dificultades. El pensamiento feminista, que tiene en su haber una ya sólida tradición histórica, ha sufrido una serie de transformaciones y de crisis internas. Asi, a una primera fase "celebratoria", durante la que, efectivamente, se aplauden esos primeros rasgos comunes que, en muchos sentidos, se han mostrado como liberadores para ambas corrientes, le sigue una reacción de cauteloso escepticismo por parte de las feministas: y es que el pensamiento de la posmodernidad continúa aferrándose a la fea y moderna costumbre de apropiarse, para sus propios fines, de lo que se ha dado en llamar "lo femenino". Si quisiéramos adoptar la jerga del momento, diríamos que el sujeto masculino prosigue, implacable, con la voraz colonización del territorio femenino. La posmodernidad, al invocar al "otro" ( $y$ ya sabemos que es una de sus invocaciones más oídas) invoca también al género femenino. Con el término de "lo femenino" se designan aquellas "virtudes"

${ }^{13}$ Barbara CREeD, "From Here to Modernity: Feminism and Postmodernism", en $A$ Postmodern Reader, ed. de J. Natoli y L. HutCHEON, p. 399.

${ }^{14}$ Aunque el concepto de "binarismo", dentro del contexto de la posmodernidad, inevitablemente remita a Derrida, 10 cierto es que las feministas han explorado y denunciado aún con mayor fervor esa metafísica de las oposiciones. Remitimos sobre todo al trabajo de Hélène Cixous citado en la bibliografía.

${ }^{15}$ B. CREED, "From Here to Modernity...", en op. cit., p. 399. 
que, según los posmodernos, fueron ignoradas e injustamente arrinconadas por la modernidad, a saber: la intuición (frente a la razón), lo local (frente a lo universal), lo privado y doméstico (frente a lo público), etcétera. Hélène Cixous añade a esta lista una poética colección de binomios suplementarios. A la pregunta: “¿Dónde está ella?", responde con las siguientes oposiciones: actividad/pasividad; sol/luna; cultura/naturaleza; día/noche; padre/madre; cabeza/ corazón; inteligible/sensible; logos/pathos. ${ }^{16}$

Pero es precisamente esta apropiación, ese gesto de presunta solidaridad, el que irrita más profundamente a las feministas, Cixous incluida. La proclamación de lo femenino como un nuevo precepto cultural acarrea consigo la funesta consecuencia de un nuevo encasillamiento de la mujer en regiones etéreas, habitadas exclusivamente por el idealismo masculino: "El engañoso concepto de lo femenino siempre ha sido empleado para negar la existencia de las mujeres 'de verdad', hechas no de aire y de sueños, sino de carne y hueso". ${ }^{17}$

La optimista versión de Craig Owens, para quien el feminismo es fenómeno característicamente posmoderno, se sostiene muy precariamente. Si bien es cierto que las feministas, olvidadas ya de la antigua melodia de la igualdad, le cantan ahora a la diferencia, como asegura el estudioso, no es menos verdadero que esa diferencia gusta mucho menos cuando se localiza en los márgenes. Hoy en día, el feminismo, olvidado de las quijotadas de antaño, huye, con gran sentido pragmático, de lo marginal; en cuanto puede, se traslada al centro, para desde allí hacerse oír.

En la era postindustrial, el lema ya no es la solidaridad femenina, ni el abierto antagonismo con el hombre, sino el justo acceso al poder, y la colonización, no de los márgenes, sino del centro. El margen (al igual que el fragmento) ha sido y todavía es para las mujeres una imposición, y nunca una elección voluntaria. Para el posmoderno (blanco, hombre, occidental), en cambio, los márgenes vuelven a ser terreno virgen, y la filosofia que los defiende, un nuevo desafio, una nueva pirueta con que ejercitar el intelecto, un nuevo continente que vuelve a llamar a la conquista.

Observamos cómo, según Owens, el feminismo reniega de toda narrativa totalizante y critica con acritud los famosos "metarrelatos" lyotardianos. Si así fuese realmente, el movimiento feminista estaría sin duda tirando piedras contra su propio tejado. Porque ¿qué es el concepto de "género" ( $y$ todo ese rosario de reflexiones, estudios críticos, libros y congresos con que se adorna) sino otro fulgurante "metarrelato"?

${ }^{16}$ Hélène Cixous, "Sorties", en New French Feminism, ed. de E. MARKs e I. de Courtivron, p. 93.

${ }^{17}$ P. WAUGH, op. cit. p. 127. 
Las objeciones hechas por el feminismo a la posmodernidad son numerosas y se hacen cada vez más patentes. Y es que, a pesar de ese presunto paralelismo cronológico ya aludido, ambas manifestaciones son fundamentalmente asincrónicas e históricamente descompensadas:

La identidad masculina, a la que tradicionalmente se le ha atribuido una ejemplar solidez y coherencia, ahora de pronto se descompone, se fragmenta y aún se solaza posmodernamente en esa fragmentación. Instalada cómodamente en el centro, resulta que de una década a esta parte añora los márgenes y hace de ellos una ruidosa propaganda.

La identidad femenina, por contra, siempre fue descentrada, hecha con retazos, y siempre estuvo acostumbrada a que la definieran otros. Fue posmoderna antes que moderna. Su sueño, ahora más vívido que nunca, no es desconstructivo o posmoderno, sino hondamente existencialista y, por tanto, moderno. En la década de los setentas, cuando los posmodernos se afanaban precisamente en proclamar la muerte del autor, el fin del humanismo y un largo y ya tedioso etcétera de finiquitos y fallecimientos, las feministas iniciaban la lenta pero firme reconstrucción de una subjetividad que no querian fragmentada, sino entera.

El decenio en el que se consagra la experimentación y fragmentación de la narrativa entre los escritores masculinos, con el Nouveau Roman a la cabeza, es a su vez el decenio en que abunda, entre las escritoras, la ficción confesional y la autobiografia. Con esa preocupación por la afirmación de la identidad a través de la biografía y sobre todo a través del testimonio autobiográfico, el feminismo, paradójicamente, hace una de sus más relevantes contribuciones al pensamiento posmoderno. Linda Hutcheon sostiene que al conceder ese nuevo y enfático valor a la noción y concepto de "experiencia" (experiencia vital, se entiende), los feminismos han destapado un asunto de capital importancia en lo que a la representación posmoderna se refiere: ¿qué es, hay que preguntarse a partir de ahora, una narrativa histórica, y en dónde reside su validez? ¿Quién decide, por otra parte, si ese relato histórico es o no legítimo? Estas interrogantes han contribuido a que los documentos narradores de vidas se sometan a una nueva revisión, y especialmente de esa parte de la existencia humana que se consideraba tradicionalmente como ajena al curso principal de la historia: diarios, cartas, confesiones, biografías, autobiografias, autorretratos. Si lo personal es lo político, como reza el famoso lema que debemos a las feministas, entonces la tradicional escisión entre historia pública y privada exige ser reformulada. En ese esfuerzo de reformulación, precisamente, posmodernidad $y$ feminismo vuelven a juntarse. ${ }^{18}$

${ }^{18}$ L. HUTCHEON, op. cit., p. 160. 
La lenta construcción de una identidad femenina topa, en la era posmoderna, con otro escollo, con otro presunto final: el fin de la historia, anunciado por Fukuyama y por Vattimo. La tan extendida desconfianza en el progreso, profusamenta analizada por Adorno y Horkheimer en La dialéctica de la Ilustración, le hace un flaco servicio al feminismo, que todavía se halla en pleno estado evolutivo y muy lejos, afortunadamente, del desencanto. Para el feminismo, la historia todavia tiene profundidad, y todavía brinda soluciones y esperanza. A la historia "profunda" dominada por la cronología se le opone esa "historia-escaparate" de la posmodernidad tan insolidaria con las feministas, en la que se exhiben caprichosos objetos sacados de todo contexto temporal.

Según Jameson, la posmodernidad es efectivamente la era de la abolición del tiempo y de la organización de la realidad alrededor de coordenadas espaciales. El feminismo, una vez más, ha de iniciar un nuevo rumbo que lo aleje, por un lado, de ciertos preceptos posmodernos poco beneficiosos y, por otro, de esos obstáculos sitos en la dinámica de su propio pensamiento. Es sabido que el feminismo moderno y ortodoxo miraba con llamativa frecuencia hacia atrás $\mathrm{y}$, ante el monótono espectáculo de una historia invariablemente misógina, caía con facilidad en el lamento: El segundo sexo de Simone de Beauvoir y el modelo de crítica literaria llamado "Imágenes de la mujer" son ejemplos paradigmáticos. Sobre el segundo ejemplo, Toril Moi comenta que "nos damos cuenta en seguida de que estudiar las imágenes de la mujer en la novela equivale a estudiar las falsas imágenes de la mujer en la novela". ${ }^{19}$ El feminismo actual, el feminismo posmoderno, ha de mirar hacia delante, que es otra manera de hacer uso de la historia y de afianzarla. Con esa nueva forma de hacer la historia (en vez de padecerla), las imágenes se tornarán de falsas en verdaderas.

Sea como fuere, lo cierto es que ambas direcciones de la mirada se apoyan firmemente en la cronologia. Quitarle a la mujer el tiempo y devolverla al espacio (como pretende hacer de nuevo la posmodernidad) es impedir —otra vez- que avance; es llevarla no a un nuevo terreno inexplorado sino a su terruño de siempre: recuérdese que la figura femenina, fuera y dentro de la literatura y del arte, siempre ha representado el espacio (casi siempre doméstico), la quietud, la "intrahistoria" unamuniana; recuérdese también que siempre ha sido el objeto privilegiado de los pasajes descriptivos, mientras que el hombre -el verdadero sujeto de la acción-es, todavia, el habitante por excelencia del tiempo y de la historia.

Intentemos, no obstante, una nueva vía de reconciliación entre feminismo y posmodernidad: según Fraser y Nicholson, tanto el feminismo como la pos-

19 Toril Mor, Teoria literaria feminista, p. 56. 
modernidad han tratado de desarrollar nuevos paradigmas de crítica social que no se basen en fundamentos filosóficos tradicionales. Han criticado las epistemologías fundacionalistas y las teorías políticas y morales para dejar claro el carácter parcial, contingente, históricamente condicionado de lo que siempre se ha hecho pasar por verdades necesarias, universales, ahistóricas frente a los ojos de la corriente principal del pensamiento. Han puesto en duda el proyecto filosófico dominante de buscar objetividad bajo el disfraz de la "visión de un ojo de Dios" que trasciende cualquier situación o perspectiva". ${ }^{20}$

¿Por qué, a pesar de todas estas similitudes de pensamiento y de intención, posmodernidad y feminismo parecen, en el fondo, irreconciliables? Creemos que Fraser y Nicholson, efectivamente, tienen razón cuando aseguran que la esencial diferencia y origen de la disputa radica en el hecho de que "a diferencia de la postmodernidad, que ha llegado a esa visión del mundo a través de un interés por el status de la filosofia, el feminismo llegó a ella a partir de los requerimientos y necesidades de la práctica política. Ese interés práctico ha salvado a la teoría feminista de muchos de los errores de la postmodernidad". ${ }^{21}$

Digamos a modo de conclusión y de advertencia, que los valores de la posmodernidad amenazan con ser, nuevamente, valores esencialmente masculinos. Reconozcamos valientemente y en contra de la opinión de moda que la historia, la cronología, "los metarrelatos" son, todavía, necesarios para la construcción y afianzamiento de la identidad femenina.

Por esa razón, Fraser y Nicholson aseguran que la crítica feminista posmoderna necesita de una teoría que sea "explícitamente histórica, a tono con la especificidad cultural de distintas sociedades y periodos y con la de distintos grupos dentro de las sociedades y los periodos". Se trata, eso sí, de una posmoderna historia con minúsculas (frente al ampuloso concepto moderno de "la" historia), adaptada a culturas e instantes concretos: "la teoría feminista posmoderna sería no-universalista. Cuando su objeto de estudio atravesara fronteras culturales y temporales, su modo de atención debería ser comparativo en lugar de universalizador". ${ }^{22}$

Sabina Lovibond responde al tan posmoderno prurito no-universalista defendido en la cita anterior con una recomendación a caballo entre la posmodernidad y la modernidad: "Los esfuerzos de las feministas no deberían centrarse exclusivamente en los diversos programas políticos de índole local. Se hace necesario instituir un programa global destinado a la abolición de un sistema de clases todavía sexista y los diferentes formas de vida interiorizada

${ }^{20}$ N. Fraser y L. Nicholson, “Crítica social sin filosofia...", en op. cit., p. 16.

${ }^{21}$ Idem.

${ }^{22}$ Ibid., p. 26. 
que de él se derivan. Este programa ha de considerarse global no solamente porque encuentra modo de aplicación en cualquier lugar del orbe, sino porque, a la postre, sus metas y propósitos vienen a coincidir con los de los demás movimientos igualitarios o liberacionistas". ${ }^{23}$

Finalmente, Fraser y Nicholson insisten en que "la teoria feminista postmoderna sería pragmática y falibilistica. Prepararía sus métodos y categorías para la tarea especifica que tuviera enfrente, utilizando categorías múltiples cuando fuera apropiado y dejando de lado la comodidad metafisica de un sólo método feminista o una sola epistemología feminista". ${ }^{24}$

"El reconocimiento de la diversidad de las necesidades y experiencias de las mujeres" constituye, sin duda y tal como aseguran Fraser y Nicholson, uno de los grandes hallazgos posmodernos de la crítica feminista. Ciertamente, el feminismo conserva integro todo su vigor, no solamente porque es un movimiento relativamente nuevo y suficientemente flexible y abierto a nuevos enfoques (como es el posmoderno multiculturalismo), sino porque su principio de acción, su "agenda", como sostiene Lovibond, sabe combinar con destreza una serie de ingredientes extraídos tanto de la modernidad como de la posmodernidad.

No obstante, la fuerza y talento verdaderos del feminsimo no radica en sus habilidades combinatorias sino en su admirable capacidad para la "resistencia". Ello nos permite nuevamente sacar útiles enseñanzas del pensamiento posmoderno y buscar otra vez la necesaria inspiración en la Escuela de Frankfurt: la resistencia - lema de los frankfurtianos, sobre todo de los pensadores de la primera generación - y motor generado de las ideas contenidas en La dialéctica de la Ilustración, ha de ser igualmente la fuerza motriz de los feminismos posmodernos: resistencia ante ciertos axiomas de modernidad, pero resistencia también, y si cabe aún más violenta y pertinaz, ante las peligrosas falacias de la posmodernidad.

\section{Bibliografia}

ADORNO, Theodor y Max HORKHEIMER, Dialéctica de la Ilustración. Madrid, Trotta, 1994.

${ }^{23}$ El ensayo de Sabina Lovibond que citamos ("Feminism and Postmodernism", 1990) apareció publicado, en versión al espanol, en Debate Feminista, núm. 5. 1993, p. 408.

${ }^{24}$ N. Fraser y L Nicholson, “Crítica social sin filosofía...”, en op. cit., p. 16. 
BARTHES, Roland, "The Death of the Author", en Image, Music, Text. Paris, Editions du Seuil/Collins, 1968.

BAUDRILlaRD, Jean, In the Shadows of Silent Majorities. Nueva York, Semiotext(e), 1983.

BAUDRILlARD, Jean, Simulacres et simulation. Paris, Galilée, 1981.

BAUdRILlard, Jean, "The Extasy of Communication". Nueva York, Semiotext(e), 1988.

BEAUVOIR, Simone de, Le deuxième sexe. París, Gallimard, 1949.

BELl, Dạiel, The Coming of Post-industrial Society. Nueva York, Basic, 1973.

BELL, Daniel, The Cultural Contradictions of Capitalism. Nueva York, Basic, 1976.

BENJAMIN, Walter, Das Kunstwerk im Zeitalter seiner technischen Reproduzierbarkeit. Francfort del Main, Suhrkamp, 1973.

BEST, Todd y Douglas Kellner, Postmodern Theory. Critical Interrogations. Nueva York, The Guilford Press, 1991.

BORDO, Susan, "Feminism, Postmodernism and Gender-Scepticism", en Feminism/Postmodernism. Ed. de Linda J. Nicholson. Nueva York/Londres, Routledge, 1990.

CIXOUS, Hélène, "Sorties", en New French Feminisms. Ed. de E. Marks e I. de Courtivron. Brighton, Harvester Press, 1981.

CREED, Barbara, "From Here to Modernity: Feminism and Postmodernism", en $A$ Postmodern Reader. Ed. de J. Natoli y L. Hutcheon. Albany, State University of New York Press, 1993.

DeleuZe, Gilles y Félix GUATTAR, Anti-Oedipus. Minneapolis, University of Minnesota Press, 1983. 
Deleuze, Guilles y Félix GUATTARI, A Thousand Plateaus. Minneapolis, University of Minnesota Press, 1987.

DERRIDA, Jacques, Margins of Philosophy. Chicago, University of Chicago Press, 1981.

DERRIDA, Jacques, Of Grammatology. Baltimore, Johns Hopkins University Press, 1976.

DERRIDA, Jacques, Speech and Phenomena, and Other Essays on Husserl's Theory of Signs. Evanston, Northwestern University Press, 1973.

FIEDLER, Leslie, "Cross the Border-Close the Gap", en The Collected Essays of Leslie Fiedler. Nueva York, Stein and Day, 1971.

FouCault, Michel, Discipline and Punish. Nueva York, Vintage Books, 1979.

FOUCAULT, Michel, El imperio de lo efimero. La moda y su destino en las sociedades modernas. Barcelona, Anagrama, 1993.

FOUCAULT, Michel, La era del vacio. Ensayos sobre el individualismo contemporáneo. Barcelona, Anagrama, 1993.

FoUCAULT, Michel, La postmodernidad (explicada a los niños). Barcelona, Gedisa, 1994.

FOUCAULT, Michel, Madness and Civilization. Nueva York, Vintage Books, 1972.

FouCaULT, Michel, Power/Knowledge. Nueva York, Pantheon Books, 1980.

FOUCAULT, Michel, "Qué era la modernidad", en El debate modernidad/ postmodernidad. Ed. de N. Casullo. Buenos Aires, Imago Mundi, 1993.

FOUCAULT, Michel, The Archeology of Knowledge. Nueva York, Pantheon Books, 1972. 
FoucaulT, Michel, The Dismemberment of Orpheus: Toward a Postmodern Literature. Madison, University of Wisconsin Press, 1971.

FouCAULT, Michel, The History of Sexuality. Nueva York, Vintage Books, 1980.

FouCault, Michel, The Postmodern Condition. Minneapolis, University of Minnesota Press, 1984.

Foucault, Michel, The Postmodern Turn: Essays on Postmodern Theory and Culture. Columbus, 1987.

FouCAULT, Michel, "What is an Author?", en Language, Counter-Memory, Practice. Selected Essays and Interviews. Ed. de Donald Bouchard. Ithaca, Cornell University Press, 1977.

FRASER, Nancy y Linda NICHOLSON, "Crítica social sin filosofia: un encuentro entre el feminismo y el posmodernismo", en Feminismo y postmodernismo. Ed. de Linda J. Nicholson. Buenos Aires, Feminaria, 1992.

FUKUYAMA, Francis, "The End of History?", en The National Interest, núm. 16. 1989, pp. 3-18.

HABERMAS, Jürgen, "Modernidad versus postmodernidad", en Modernidad y postmodernidad. Ed. de Josep Picó. Madrid, Alianza, 1992.

Histoire de la vie privée, Philippe Ariès y George Duby, eds. París, Éditions du Seuil, 1987.

HUTCHEON, Linda, The Politics of Postmodernism. Londres/Nueva York, Routledge, 1993.

JAMESON, Frederic, Ensayos sobre el postmodernismo. Buenos Aires, Imago Mundi, 1991.

KrISTEVA, Julia, "Women's Time”, en Feminisms. An Anthology of Literary Theory and Criticism. Ed. de R. Warhol y D. Price Herndl. New Brunswick, Rutgers University Press, 1993. 


\section{4}

FEMINISMO Y POSMODERNIDAD

LACLAU, Ernesto, "Politics and the Limits of Modernity", en Postmodernism. $A$ Reader. Ed. de Th. Docherty. Nueva York, Columbia University Press, 1993.

MARCUSE, Herbert, An Essay on Liberation. 1968.

MARCUSE, Herbert, One-Dimensional Man. Boston, Beacon Press, 1964.

Modernidad y postmodernidad. Ed. de J. PIcó. Madrid, Alianza, 1992.

MoI, Toril, Teoría literaria feminista. Madrid, Cátedra, 1988.

OWENS, Craig, "El discurso de los otros: las feministas y el posmodernismo", en La postmodernidad. Ed. de H. Foster. Barcelona, Kairós, 1983.

Rodriguez MAGDA, Rosa María, La sonrisa de Saturno. Hacia una teoria transmoderna. Barcelona, Anthropos, 1989.

SONTAG, Susan, Against Interpretation. Nueva York, Deli, 1966.

TODD, Janet, Feminist Literary Theory. Nueva York, Routledge, 1988.

VATTIMO, Gianni, The End of Modernity. Oxford/Baltimore, Polity and Johns Hopkins University Press, 1985.

WaUgh, Patricia, Practising Postmodernism. Reading Modernism. Londres/Nueva York, Edward Arnold, 1992. 